\title{
Therapeutic Medical Thoracoscopy
}

\author{
P.A. Mori, A.G. Casalini
}

Monaldi Arch Chest Dis 2011; 75: 1, 89-94.

Keywords: Thoracoscopy, Pleurodesis, Talc poudrage, Talc slurry, Pleural effusion.

U.O. di Pneumologia e Endoscopia Toracica, Azienda Ospedaliero-Universitaria di Parma, Italy.

Correspondence: Dr. PA Mori, U.O. di Pneumologia e Endoscopia Toracica, Azienda Ospedaliero-Universitaria di Parma, Via Gramsci, 43100 Parma, Italy; e-mail: pmori@ao.pr.it

The medical thoracoscopy is a safe and efficacious methodology allowing the interventional pneumologist to make the diagnosis of the pleural pathology [1] and the therapy of a a great deal of pleural diseases. The main therapeutic indications are made by the pleurodesis during pleural effusion or pneumothorax and by the treatment of the empyema.

\section{Pleurodesis during malignant pleural effusion}

During recidivist neoplastic pleural effusion the medical thoracoscopy offers, as a therapeutic possibility, a precocious and efficacious treatment, the pleurodesis, stopping the relapse of the effusion.

Through the production of a (chemical or mechanical) pleural fibrosis, the pleurodesis determines the symphysis between the two pleural layers (parietal and visceral) obtaining the obliteration of the pleural space with the aim of limiting or avoiding completely the production of liquid, cause of symptoms and of disablement for the patient [2].

\section{Indications}

There are indications to the pleurodesis when:

- the aetiological treatments have failed or are not available;

- the patient gets relief from the thoracentesis;

- the requirements are present for the re-expansion of the lung: absence of bronchial obstruction; there is a (neoplastic or non) thickening of the visceral pleura obstructing the expansion of the lung ("trapped lung") and so the capability of the lung of re-establish contact with the parietal pleura; there is not a carcinomatous lymphangitis.

The missed pleurodetic treatment drives to repeated thoracentesis with resulting possible collateral effects:

- waste of proteins;

- discomfort for the patient;

- complications by thoracentesis such as iatrogenic pneumothorax, cardiovascular collapse, ex-vacuo pulmonary oedema;

- empyema of the pleural cavity;

- neoplastic risk of the chest wall especially in case of mesothelioma.

\section{Selection of the patients}

In order to reduce the onset of adverse events influencing the morbidity or the mortality of the pleurodesis it is useful to carefully evaluate the patient before the execution of the indications. Some authors have indicated the measurement of the pleural liquid $\mathrm{pH}$ as a factor able to foresee a favourable result of the talc poudrage (TP). In particular a $\mathrm{pH}>7.20$ could represent a favourable index $[3,4]$, meaning a pleura still relatively undamaged by neoplastic infiltration. However more recently a meta-analysis has pointed out that the $\mathrm{pH}$ is an insufficient prediction index [5]. On the contrary it is fundamental that the lung can re-expand completely after the pleurodesis [6].

The evaluation of the performance status (PS) measured using the Karnofsky index [7] allows an evaluation of the clinical conditions of the patient. In particular a Karnofsky performance scale score $<40$ seems to contra-indicate the thoracoscopic pleurodesis. The patients with a life prognosis lower than one month [8] should not undergo pleurodesis. A careful selection of the patients evaluating the PS, the general clinical and respiratory conditions, the comorbidity and the life expectations should therefore be made to decide if the pleurodesis is to be carried out and which methodology is best to use (Level of evidence: III).

\section{Recommendation}

- In patients in which the complete drainage of the liquid and the pulmonary re-expansion are documentable and exclude the presence of a "trapped lung", the pleurodesis has to be attempted (Grade B).

\section{Methodology}

The ideal agent able to induce sclerosis agent is one with high, immediate and durable efficacy, low cost and easy availability, easiness of administration. Between the different agents able to induce 
the pleurodesis [9] the talc is certainly the most used substance [10]. The Talc $\left(3 \mathrm{MgO}, 4 \mathrm{SiO}_{2}\right.$ and $\mathrm{H}_{2} \mathrm{O}$ ) acts stimulating an inflammatory process in the mesothelial cell, producing an increase of the Interleukin-8, that acts in its turn as chemotactical agent for the neutrophils, starting a multifactorial process not well known yet, driving to the pleural fibrosis [11]. The talc pleurodesis during medical thoracoscopy is a methodology within the competence of the doctor, in particular of the pneumologist, which is recognised and largely used [1] (Level of evidence: $I b$ ).

The talc can be insufflated in pleural cavity directly through thoracoscopic duct (TP) [12] or through a thoracotomic drainage as slurry (talc slurry) (TS) [13]. Despite the wide use of the talc as a chemical substance there is a wide variability in the techniques employed to induce pleurodesis with talc. This fact determines different results in terms of efficacy and of incidence and nature of the collateral effects [14].

The BTS Guidelines [15] recognise that the thoracoscopy should be considered for the management of the malignant relapsing pleural effusion. However the BTS guidelines do not indicate the best strategy to induce pleurodesis. An important meta-analysis [16] has allowed explaining some fundamental points:

- the use of a chemical substance able to induce sclerosis has resulted better than the simple thoracotomic drainage to obtain with success the pleurodesis;

- the best substance for the pleurodesis is the talc;

- TP is more efficacious than the talc introduced through the thoracotomic drainage as slurry (TS);

- there are no differences between the two methodologies concerning the mortality.

More recently an intergroup study on wide survey has shown no differences between the two methodologies, TS and TP, in the malignant pleural effusion [17]. Analysing however the subgroups, the data indicates a larger efficacy of TP in the patients with pleural metastasis of lung cancer or breast cancer.

In the choice between TP and TP the clinical evaluation is very important. The pre-surgical evaluation of the risk factors has allowed some parameters to be highlighted such as a recent chemotherapy, the need for oxygen treatment and the peripheral oedema, that can be predictors of an acute respiratory failure that can follow the TP [18].

Also the clinical signs often determine for us which kind of methodology to use. A low PS, the age of the patient, the life expectations [6], the presence of pleural liquid in higher quantity than 2 litres with the risk of pulmonary oedema by re-expansion and the lacking tolerance of the patient during the thoracoscopic action (cough, pain, agitation, arrhythmias and desaturation during the execution of the thoracoscopy) are included in the clinical data that should induce the pneumologist to prefer the TS (Level of evidence: I).

During the thoracoscopy it is not imperative to proceed immediately to the TP. In a pleural effu- sion that has not been diagnosed, in order to find a neoplastic situation, particularly in a patient that is unlikely to undergo chemotherapy or surgical operation, the pneumologist is induced to proceed directly to the talc pleurodesis. If, on the contrary, the thoracoscopic situation is characterised by a pleural thickening without evident neoplastic situations, it is advisable to wait for the results of the histologic examination before proceeding to the pleurodetic action. In fact it could be necessary to make a second diagnostic thoracoscopy [19]. In these cases the TS methodology is generally used; it will be carried out to the patient in his bed when the histological examination is ready (Level of evidence: IV).

\section{Recommendations}

- Thoracoscopy combined with the use of a substance able to induce pleural sclerosis is an advisable methodology for the management of the pleural effusion and is better than simple thoracic drainage. The best substance is represented by the talc (Grade A).

- The pleurodesis with TP has more effective results than the pleurodesis with TS, in particular in the pleural metastasis of lung cancer or breast cancer. There are no differences between the two methodologies concerning the mortality (Grade A).

- During the thoracoscopy the pleurodesis has not to be applied at all. If the macroscopic situation is evidently neoplastic and there are no expectations of surgical operations or intracavitary chemotherapy, the TP can be made. In uncertain situations, considering the possibility of having to repeat the examination, it is better to apply drainage and wait for the histological examination (Grade C).

\section{Complications}

A number of studies have confirmed the efficacy of the talc through thoracoscopic duct with a success percentage variable from survey to survey with values between 72 and $90 \%[8,14,17,20]$.

The thoracoscopic pleurodesis with talc lists fever and thoracic pain among its main complications.

The safety of the methodology has, however, been intensely debated [21], especially concerning the highlighting of episodes of acute respiratory insufficiency such as Adult Respiratory Distress Syndrome in some surveys $[8,15,22]$. Some authors have expressed concerns regarding the talc poudrage [21-23], while others have underlined the safety of the methodology [10, 24, 25]. 
There can be a number of different causes which can explain an acute respiratory failure secondary to the talc insufflation:

- systemic inflammatory reaction

- re-expansion pulmonary oedema

- excessive talc dosage $[22,26]$

- sepsis by talc bacterial contamination

- end stage COPD

- restrictive pulmonary disorders due to pulmonary neoplasm or fibrosis

- excessive premedication

- diffused metastatic disease

- terminal stage due to any disorder

- significant differences in the dimensions of the talc particles in the various preparations [27]

- presence of contaminant ores such as calcite, quartz, chlorite, dolomite

- contemporaneous wide pleural biopsies.

It has been demonstrated that the talc packets are differ from one country to another and that the chemical and physical characteristics of the talc used should always be specified in the scientific studies. Using preparations containing talc particles $<5$ microns an increase of morbidity is obtained [18-28]. The thoracoscopic insufflation of small talc quantities, using preparations with particles $>10$ microns, does not determine any respiratory complications $[6,29]$ (Level of evidence: III).

\section{Recommendation}

- In order to avoid the onset of Acute Lung Injury the following technical notes are advisable: - do not exceed 5 g. talc - use talc particles with diameter $>\mathbf{1 0}$ microns - avoid the bilateral pleurodesis in the same surgical session (Grade B).

\section{Technical notes}

At the end of the thoracoscopic examination, all the pleural liquid has to be removed before the talc insufflation [30]. The removal is easy and safe during the thoracoscopy, also with large quantities of liquid, because the air enters passively the thoracic cavity creating a balance of pressures and avoiding therefore the risk of ex-vacuo pulmonary oedema.

The talc (Luzenac Co., France) in quantities varying between 2 and $4 \mathrm{~g}$ is pulverised using a double-balloon insufflator [31] to avoid excessive insufflation pressures. It is then necessary to examine the pleural cavity with the thoracoscope to control the regular distribution on all the pleural surfaces.

Finally a thoracic drainage Trocar $24 \mathrm{~F}$ is applied. A suction with negative pressure of at least 20-40 $\mathrm{cm} \mathrm{H}_{2} \mathrm{O}$ is applied, using a water valve formed by a series of two water bottles. The patient has to stay in bed connected to the aspirator continuously for the first 24 hours which are the most important for the success of the pleurodesis.
It is necessary to avoid the administration of steroids and FANS that can influence negatively the pleural inflammatory reaction. The pleurodesis can be considered successful when the quantity of liquid is lower than $100 \mathrm{ml}$ in the 24 hours (Level of evidence: $I V$ ).

\section{Recommendation}

- The thoracoscopic pleurodesis has to be preceded by the complete removal of the liquid. At the end a thoracic drainage $24 \mathrm{~F}$ is applied and suction with negative pressure is made using a water valve. The patient has to be connected to the aspirator continuously for the first 24 hours. The administration of steroids or fans has to be avoided. The pleurodesis is successful if the quantity of drained liquid is lower than $100 \mathrm{ml}$ in the 24 hours (Grade C).

Thoracoscopic pleurodesis during non-neoplastic recidivist pleural effusion

The pleurodesis treatment of the non-neoplastic pleural effusions has not been studied by randomised and controlled trials. The techniques used are both TS and TP. The aetiology of the non-neoplastic effusion is various and is mainly represented by [32]: cirrhosis of the liver, recidivous pleural effusion after Aortic-Coronary By-Pass, congestive heart failure, Dressler syndrome, nephrosis syndrome, yellow nails syndrome, chylothorax, amyloidosis and pleurisy during LES. Even though it is evident that the thoracoscopy and therefore the TP have, if compared to the talc slurry, the fundamental advantage of allowing an aetiological diagnosis, there are no sure and obvious evidences in favour of one of the two methodologies [33] (Level of evidence: IV).

\section{Recommendation}

- The talc is the most efficacious substance able to induce pleurodesis during non-neoplastic pleural effusion. Do not exceed $5 \mathrm{~g}$ talc (Grade C).

\section{Thoracoscopic pleurodesis during pneumothorax}

The pneumothorax (pnx) is the presence of air in the pleural space determining the loss of the negative pressure and a variable degree of pulmonary collapse. The treatment of the first episode of spontaneous pnx can vary, according to the extent of the pnx, from the simple observation, to the simple suction with needle or to the application of a thoracic drainage [34]. There is also a more invasive clinical-surgical treatment for the preven- 
tion and the treatment of the relapses. With the surgical methodologies such as the Video Assisted Thoracoscopic Surgery (VATS) [35], the medical thoracoscopy and the TP through thoracoscopic duct play an important role [36, 37]. The removal of the blebs represents the recognised therapy for the treatment of the relapses. However several anatomo-pathological studies have not succeeded in demonstrating the place of the aerial losses in the lesions such as blebs. It is possible that the cause of the primary spontaneous pnx is an increase of the pleural porosity. For this reason, the talc pleurodesis has a fundamental role in the control of relapses, determining a pleural inflammation [38].

In the treatment of the pneumothorax the thoracoscopic TP has proved to be more efficacious than the talc slurry. The advised talc dosage is 5 $\mathrm{g}[39]$.

It has to be highlighted that the talc pleurodesis during pnx determines an inflammation on a undamaged pleura, producing a very painful reaction in the great part of the subjects. This factor could encourage the choice of a surgical technique such as the VATS foreseeing a general anaesthesia [40].

There are no randomised and controlled studies comparing the efficacy of the medical thoracoscopy and the TP with the other surgical techniques such as for example the VATS and so the best technique to use has not been determined yet [41] (Level of evidence: IV).

\section{Recommendation}

- In the treatment of the spontaneous pnx relapse the TP medical thoracoscopy is better than the TS pleurodesis (Grade $\mathbf{C}$ ).

\section{Empyema}

Empyema is the pus deposit in the pleural cavity, while the parapneumonic effusion is each pleural effusion combined with bacterial pneumonia, pulmonary abscess or bronchiectasis. In relation to the matter, the identification of a complicated parapneumonic pleural effusion is of great importance [42]. It is identifiable on the basis of one or more of these parameters supplied by the thoracentesis:

1. pleural liquid $\mathrm{pH}<7.20$

2. pleural liquid LDH $>1000 \mathrm{IU} / \mathrm{l}$

3 . positive microbiological cultures on the pleural liquid.

In the case of complicated pleural effusion or of empyema it is efficacious to apply a pleural drainage and to administer an intrapleural fibrinolitic therapy and an antibiotic therapy. If in a maximum of 7 days there is no clinical improvement, the thoracoscopic approach is indicated [43].

Today the (medical or surgical) thoracoscopy is considered the best treatment when the therapy with thoracotomic drainage, fibrinolitics and antibiotics has failed [44]. The success of the medical thoracoscopy depends on the possibility of a correct diagnosis in the complicated effusions secondary to morbid conditions such as tuberculosis or tumours and of the execution at the same time of the debridement of the adhesions, the removal of the infected material, so assuring the pulmonary re-expansion.

The type and the phase of the pleural infectious process are the fundamental factors that determine the need to the thoracoscopy and the relative definitive result. When the pleural liquid is multi-loculated there is a complicated empyema. The access with the thoracentesis is difficult and dangerous because of a possible iatrogenic pneumothorax. In that case the thoracoscopy is suitable [45] (Level of evidence: IV).

\section{Recommendation}

- The medical thoracoscopy is suitable in case of multiloculated empyema to introduce a large drainage in right position (Grade C).

\section{Summary of Recommendations}

- In patient where the complete drainage of the liquid and the pulmonary re-expansion are documentable and exclude the presence of a "trapped lung", the pleurodesis has to be attempted (Grade B).

- Thoracoscopy combined with the use of a substance able to induce pleural sclerosis is an advisable methodology for the management of the pleural effusion and is better than the simple thoracic drainage. The best substance is represented by the talc (Grade A).

- During the thoracoscopy the pleurodesis should not be applied at all. If the macroscopic situation is evidently neoplastic and there are not expectations of surgical operations or intracavitary chemotherapy, the TP can be made. In uncertain situations, considering the possibility of having to repeat the examination, it is better to apply drainage and wait for the histological examination (Grade C).

- In order to avoid the beginning of Acute Lung Injury the following technical notes are advisable: - do not exceed $5 \mathrm{~g}$ talc - use talc particles with diameter $>\mathbf{1 0}$ microns avoid the bilateral pleurodesis in the same surgical session (Grade B). 
- The thoracoscopic pleurodesis has to be preceded by the complete removal of the liquid. At the end a thoracic drainage $24 \mathrm{~F}$ is applied and suction with negative pressure is made using a water valve. The patient has to be connected to the aspirator continuously for the first 24 hours. The administration of steroids or fans has to be avoided. The pleurodesis is successful if the quantity of drained liquid is lower than $100 \mathrm{ml}$ in the $\mathbf{2 4}$ hours (Grade C).

- In the treatment of the spontaneous pnx relapse the TP medical thoracoscopy is better than the TS pleurodesis (Grade $\mathbf{C}$ ).

- The medical thoracoscopy is suitable in case of multiloculated empyema to introduce a large drainage in right position (Grade C).

\section{References}

1. Wahidi MM, Herth FJF, Ernst A. State of the art: Interventional Pulmonology. Chest 2007; 131: 261-274.

2. Light RW. Pleural Diseases (4th ed). Lippincot Williams \& Wilkins. Philadelphia. 2001.

3. Rodriguez-Panadero F. Current trends in pleurodesis. Curr Opin Pulm Med 1997; 3: 319-325.

4. Rodriguez-Panadero F, Antony VB. Pleurodesis: state of the art. Eur Respir J 1997; 10: 1648-1654.

5. Heffner JE, Nietert PJ, Barbieri C. Pleural fluid $\mathrm{pH}$ as a predictor of survival for patients with malignant pleural effusions. Chest 2000 117: 79-86.

6. Stefani A, Natali P, Casali C, et al. Talc poudrage versus talc slurry in the treatment of malignant pleural effusion. A prospective comparative study. Eur J Cardiothoracic Surgery 2006; 30: 827-832.

7. Burrows CM, Mathews WC, Colt HG. Predicting survival in patients with recurrent symptomatic malignant pleural effusions. Chest 2000;117: 73-78.

8. Milanez de Campos JR, Vargas FS, Werebe EC, et al. Thoracoscopy Talc poudrage. A 15-year Experience. Chest 2001; 119: 801-806.

9. Walker-Renard PB, Vaughan LM, Sahn SA. Chemical pleurodesis for malignant pleural effusions. Ann Intern Med 1994; 120: 56-64.

10. Viallat J, Rey F, Astoul P. Thoracoscopic talc poudrage pleurodesis for malignant effusions. A review of 360 cases. Chest 1996; 110: 1387-1393.

11. Anthony VB, Nasreen N, Mohammed KA, et al. Talc pleurodesis. Basic Fibroblast Growth Factor mediates pleural fibrosis. Chest 2004; 126: 1522-1528.

12. Boutin C, Viallat JR, Cargnino P, et al. Thoracoscopy in malignant pleural effusions. Am Rev Respir Dis 1981; 124: 588-592.

13. Antony VB, Loddenkemper R, Astoul P, et al. Management of malignant pleural effusions. Eur Respir $J$ 2001; 18: 402-419.

14. Gary Lee YC, Baumann MH, Maskell NA, et al. Pleurodesis practice for malignant pleural effusions in Five English-speaking countries. Survey of pulmonologists. Chest 2003; 124: 2229-2238.

15. Antunes G, Neville E, Duffy J, et al. BTS guidelines for the management of malignant pleural effusions. Thorax 2003; 58: 29-38.
16. Shaw P, Agarwal R. Pleurodesis for malignant pleural effusions. The Cochrane database of Systematic Reviews 2004; 1: 1-42.

17. Dresler CM, Olak J, Herndon II JE, et al. Phase III Intergroup study of talc poudrage vs. talc slurry sclerosis for malignant pleural effusions. Chest 2005; 127: 909-915.

18. Kuzniar TJ, Blum MG, Kasibowska-Kuzniar K, et al. Predictors of acute lung injury and severe hypoxemia in patients undergoing operative talc pleurodesis. Ann Thorac Surg 2006; 82: 1976-1981.

19. Margery J, Le Pimpec-Barthes F, Bonardel G, et al. Quel bilan préthérapeutique faut-il proposer à un patient porteur d'un mésothèliome pleural malin? Rev Mal Respir 2006; 23: 11S45-11S50.

20. Diacon AH, Wyser C, Bolliger CT, et al. Prospective randomized comparison of thoracoscopic talc poudrage under local anesthesia versus bleomycin instillation for pleurodesis in malignant pleural effusions. Am J Respir Crit Care Med 2000; 162: 1445-1449.

21. Janssen JP. Is thoracoscopic talc pleurodesis really safe? Monaldi Arch Chest Dis 2004; 61: 35-38.

22. Rehse DH, Aye RW, Florence MG. Respiratory failure following talc pleurodesis. Am J Surg 1999; 177: 437-440.

23. Light RW. Talc should not be used for pleurodesis. Am J Respir Crit Care Med 2001; 163: 2023-2026.

24. Sahn SA. Talc should be used for pleurodesis. Am J Respir Crit Care Med 2001; 163: 2023-2026.

25. Kolschmann S, Ballin A, Gillissen A. Clinical efficacy and safety of thoracoscopic talc pleurodesis in malignant pleural effusions. Chest 2005; 128: 1431-1435.

26. Sahn SA. (2005) Choice of agents for pleurodesis. UpToDate (database on line) www.uptodate.com

27. Ferrer J, Villarino MA, Tura JM, et al. Talc preparations used for pleurodesis vary markedly from one preparation to another. Chest 2001; 119: 1901-1905.

28. Sanchez C, Marchi E, Romero B, et al. Association of the size of talc particles with the occurrence of complications of pleurodesis. Eur Respir J 2001; 18: 515-516.

29. Astoul P, Fraticelli A, Robaglia-Schlupp A, et al. Talc for pleurodesis. Hero or Villain? Chest 2003; 124: 416-417.

30. American Thoracic Society. Management of malignant pleural effusions. Am J Respir Crit Care Med 2000; 162: 1987-2001.

31. Boutin C, Viallat JR, Aelony Y. Practical Thoracoscopy. Springer ed. New York, 1991.

32. Glazer M, Berkman N, Lafair J Set, et al. Successful Talc slurry pleurodesis in patients with nonmalignant pleural effusions. Report of 16 cases and review of the literature. Chest 2000; 117: 1404-1409.

33. Sahn SA. Chemical Pleurodesis for non-malignant pleural effusions. UpToDate (database on line) www.uptodate.com

34. Baumann MH, Strange C, Heffner JE, et al. Management of spontaneous pneumothorax: an American College of Chest Physicians Delphi Consensus Statement. Chest 2001; 119: 590-602.

35. Doddoli C, Barlési F, Fraticelli A, et al. Video-assisted thoracoscopic management of recurrent primary spontaneous pneumothorax after prior talc pleurodesis: a feasible, safe and efficient treatment option. Eur J Cardiothoracic Surg 2004; 26: 889-892.

36. Casalini AG, Cavaliere S, Consigli GF, et al. Standard operativi e linee guida in endoscopia toracica. Rassegna di Patologia dell'Apparato Respiratorio 1997; 12: 293-355.

37. Lee P, Yap WS, Pek WY, et al. An audit of medical thoracoscopy and talc poudrage for pneumothorax prevention in advanced COPD. Chest 2004; 125: 1315-1320.

38. Tschopp JM, Rami-Porta R, Noppen M, et al. Management of spontaneous pneumothorax: State of the art. Eur Respir J 2006; 28: 637-650.

39. Henry M, Arnold T, Harvey J. BTS guidelines for the management of spontaneous pneumothorax. Thorax 2003; 58 (suppl II): 39-52. 
40. Van Schil PE, Hendriks JM, De Maeseneer MG, et al. Current management of spontaneous pneumothorax. Monaldi Arch Chest Dis 2005; 63: 204-212.

41. Nosenzo M. Lo Pneumotorace. In Pneumologia Interventistica A.G. Casalini ed. Springer 2006; pp. 547-554.

42. Colice GL, Curtis A, Deslauriers J, et al. Medical and surgical treatment of parapneumonic effusions: an evidence-based guideline. Chest 2000; 118: 1158-1171.
43. Davies CWH, Gleeson FV, Davies RJO. BTS guidelines for the management of pleural infection. Thorax 2003; 58: 18-28.

44. Bouros D, Hamm H. Infectious pleural effusions. Eur Respir Mon 2002; 22: 204-218.

45. Astoul P. Trattamento medico. In Pleuropatie Infettive ed Empiema Pleurico. Atti XII Corso di Toracoscopia. Brescia, 2002: pp. 133-142.

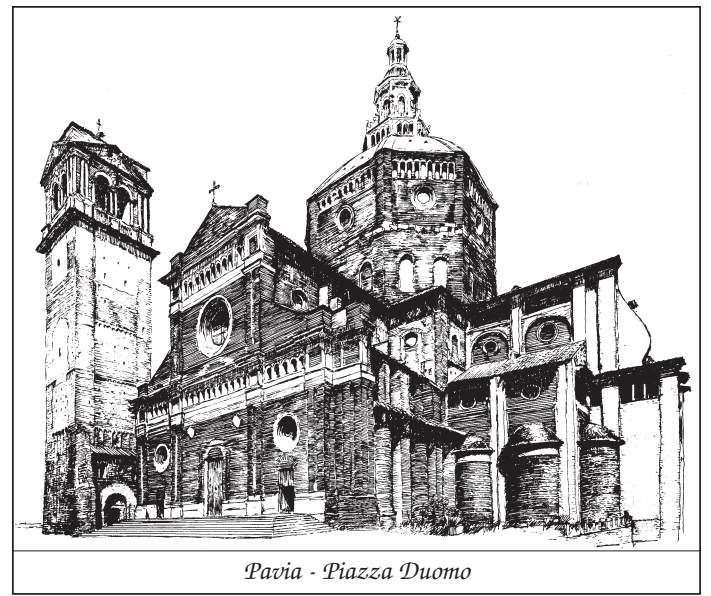

